\title{
Chronic Critical Illness: Are We Just Adding Years to Life?
}

\author{
Nagarajan Ramakrishnan (ㅇ \\ Indian Journal of Critical Care Medicine (2020): 10.5005/jp-journals-10071-23831
}

Chronic critical illness (CCI) patients require prolonged specialized care for months or years and remain a challenge for intensive care professionals and healthcare. ${ }^{1}$ It is common in the elderly although the incidence is noted to decline in the very elderly due to an increase in early mortality in that age-group. ${ }^{2}$ Modern lifesustaining technologies allow us to keep patients alive despite ongoing life-threatening illnesses. However, this comes with a price including cognitive and functional restrictions, the burden of decision-making for caregivers, and the impact on the healthcare system at large. ${ }^{3}$

The Pareto principle, also known as the $80-20$ rule is relevant in healthcare in many ways. A rather small number of people $(20 \%)$ utilize the majority $(80 \%)$ of health-care consultations and hospital admissions. ${ }^{4}$ The majority (80\%) of an individual's healthcare needs and expenses are in the last $20 \%$ of their lives. It is also estimated that $80 \%$ of the cost of care is spent in the initial $20 \%$ of the hospital stay. However, this may not apply to those with $\mathrm{CCl}$ as costs may surge during the hospitalization with clinical changes requiring additional interventions and therapies that may be expensive.

Intensive care units (ICUs) are traditionally considered to be expensive, ${ }^{5}$ and every attempt is made to transfer patients out to other areas based on the level of care required. The venue of care of CCI may vary based on the facility and the health-care system. In most countries, step-down units, high dependency units, or transitional care units provide a lower cost option to provide monitored multidisciplinary care. In countries such as the United States, where healthcare is predominantly driven by third-party insurance payers, specialized long-term acute care hospitals and skilled nursing facilities provide an alternative venue of care. However, stringent protocols and guidelines on the level of care that they could provide prompt readmission to hospitals when the patient has any significant changes in clinical status. Patients and families continue to exercise their choice in such payment models despite attempts by the treating team to explain the overall prognosis and quality of life measures. Strategies for effective communication should be implemented for shared decisionmaking in this scenario. ${ }^{6}$ If survival remains the only goal of therapy, we continue to "cheat" life at any cost.' In predominantly socialized health-care systems such as the National Health Service in the United Kingdom, European countries, Canada, and Australia, the cost of continued care is borne by the government and indirectly by the tax payers. Measures are adopted to provide this long-term care in dedicated wards as ICU beds are limited and in high demand. While efforts are made to cover medically necessary services, some of these countries limit coverage for services such as home health or medications. ${ }^{7}$ In countries such as India, where payment for healthcare is largely "out of pocket," decisions by the family are not uncommonly driven by the ability to pay for continued
Department of Critical Care Medicine, Apollo Hospitals, Chennai, Tamil Nadu, India

Corresponding Author: Nagarajan Ramakrishnan, Department of Critical Care Medicine, Apollo Hospitals, Chennai, Tamil Nadu, India, Phone: +91 9840855115, e-mail: ram@icuconsultants.com

How to cite this article: Ramakrishnan N. Chronic Critical Illness: Are We Just Adding Years to Life? Indian J Crit Care Med 2020;25(5):482-483.

Source of support: Nil

Conflict of interest: None

care. This is changing over the years with initiatives on healthcare coverage provided by government and private payers but still largely inadequate to cover prolonged illnesses. ICU at home is evolving as a more cost-efficient option in this scenario although adding significant physical, mental, and financial burden to the families. In this study, "talk turkey" about their observations in a retrospective cohort from an academic center, the authors observed that patients with hemodynamic instability requiring vasopressors and those with neurological comorbidities were at greatest risk of $\mathrm{CCl}$. Not surprisingly significant number of patients with $\mathrm{CCl}$ were tracheostomized. The cost for a patient with $\mathrm{CCl}$ was six-fold while mortality was also significantly higher. The authors do not clearly specify if some of the extended care could have been provided in alternative venues in their facility to reduce the ICU length of stay.

$\mathrm{CCl}$ leads to sleepless nights for the patient and the family. It is indeed appropriate to apply a concept similar to Spielman's 3P model of chronic insomnia ${ }^{8}$ while managing patients with $\mathrm{CCl}$ by evaluating the following aspects:

- Predisposing factors that include the comorbidities (particularly neurological) that lead to hospitalizations but not necessarily always requiring critical care.

- Precipitating factors such as noncompliance or infections leading to acute on chronic organ failure necessitating organ supports such as ventilation, hemodynamic support, and renal replacement therapy.

- Perpetuating factors including malnutrition, dyselectrolytemia, pressure ulcers, nosocomial infections, iatrogenic issues, and physical aspects such as delayed mobility.

I would like to propose that we evaluate larger cohorts of $\mathrm{CCl}$ to develop and validate a scoring system based on the above factors to assist with additional 3Ps in the management which should include the following aspects:

- Prevention-which begins from efficient chronic disease management and also promptly addressing precipitating and perpetuating factors

(-) The Author(s). 2020 Open Access This article is distributed under the terms of the Creative Commons Attribution 4.0 International License (https://creativecommons. org/licenses/by-nc/4.0/), which permits unrestricted use, distribution, and non-commercial reproduction in any medium, provided you give appropriate credit to the original author(s) and the source, provide a link to the Creative Commons license, and indicate if changes were made. The Creative Commons Public Domain Dedication waiver (http://creativecommons.org/publicdomain/zero/1.0/) applies to the data made available in this article, unless otherwise stated. 
- Prognostication - to assist the family with patient-centered decision

- Palliation-when appropriate

By utilizing this model, we will be in a position to create value-based programs to provide more appropriate care for those with a chronic critical illness.

Mortality has been the most studied outcome in critical illness, and we experience a moment of triumph about increased survival with advances in technologies and therapies. But are we only adding years to life without being considerate of the quality of life added to those years? ${ }^{9}$ Are we saving patients or creating victims? ${ }^{10,11}$ Are we communicating efficiently to assist with the decision-making? And most importantly, whose life and money is it anyway? Time to ponder.

\section{OrCIDS}

Nagarajan Ramakrishnan @ https://orcid.org/0000-0001-5208-4013

\section{References}

1. Maclntyre NR. Chronic critical illness: the growing challenge to health care. Respir Care 2012;57(6): 1021-1027. DOI: 10.4187/ respcare.01768.

2. Kahn JM, Le T, Angus DC, Cox CE, Hough CL, White DB, et al. The epidemiology of chronic critical illness in the United States. Crit Care Med 2015; 43(2): 282-287. DOI: 10.1097/ccm.0000000000000710.
3. Nelson JE, Cox CE, Hope AA, Carson SS. Chronic critical illness. Am J Respir Crit Care Med 2010; 182:446-454. DOI: 10.1164/ rccm.201002-0210ci.

4. Naoum V, Kyriopoulos D, Charonis A, Athanasakis K, Kyriopoulos J. The pareto principle ("80-20 Rule") in healthcare services in Greece. Value Health 2016; 19(7): A618. DOI: 10.1016/j.jval.2016.09.1563.

5. Ramakrishnan N. Critical economics of life and death: intense + expensive care = intensive care? Indian J Crit Care Med 2013; 17: 67-68. DOI: 10.4103/0972-5229.114817.

6. Nelson JE, Mercado AF, Camhi SL, Tandon N, Wallenstein S, August Gl, et al. Communication about chronic critical illness. Arch Intern Med 2007; 167(22): 2509-2515. DOI: 10.1001/ archinte.167.22.2509.

7. Lee $\mathrm{KH}$, Angus DC, Abramson NS. Cardiopulmonary resuscitation: what cost to cheat death? Crit Care Med 1996; 24(12): 2046-2052. DOI: 10.1097/00003246-199612000-00019.

8. Spielman AJ, Caruso LS, Glovinsky PB. A behavioral perspective on insomnia treatment. Psychiatr Clin North Am 1987; 10(4): 541-553. DOI: 10.1016/s0193-953x (18)30532-x.

9. Vijayaragavan BKT, Ramakrishnan N. Survivorship and (QALY)ty: in pursuit of a mirage? Indian J Crit Care Med 2019; 23: 111-112. DOI: 10.5005/jp-journals-10071-23130.

10. Loss SH, Nunes DSL, Franzosi OS, Salazar GS, Teixeira C, Vieira SRR. Chronic critical illness: are we saving patients or creating victims? Rev Bras Terap Intensiva 2017; 29:87-95. DOI: 10.5935/0103-507x.20170013.

11. Yıldırım S, Durmaz Y, Şan Y, Taşkıran I, Cinleti BA, Kirakli C. Cost of Chronic Critically III Patients to the Healthcare System: A Singlecenter Experience from a Developing Country. Indian J Crit Care Med 2021;25(5):519-523. 